\title{
ERRATUM
}

\author{
M. Oberbaum $\cdot$ SR. Singer $\cdot$ I. Yaniv $\cdot$ LS. Freedman \\ D. Branski
}

\section{Reply to EJCP 2004-0275 and 2004-0350}

Published online: 22 July 2005

(C) Springer-Verlag 2005

\section{Eur J Clin Pharmacol (2005) 61:67}

In the Letter to the editor "Reply to EJCP 2004-0275 and 2004-0350. (Eur J Clin Pharmacol. March 2005; 61:67)", the names of the coauthors were inadvertently omitted. The names and affiliations are shown above.

The online version of the original article can be found at http:// dx.doi.org/10.1007/s00228-004-0885-2

M. Oberbaum $(\varangle) \cdot$ S. Singer

The Center for Integrative Complementary Medicine,

Shaare Zedek Medical Center, P.O. Box 3232,

Jerusalem, 91031, Israel

E-mail: oberbaum@netvision.net.il

Fax: +972-2-6666975

I. Yaniv

Tel-Aviv University, Bone-Marrow Transplantation Unit,

The Schneider Children's Medical Center of Israel,

Rabin Medical Center, Petach Tikva,

Sackler School of Medicine, Tel-Aviv, Israel

L. Freedman

Bar-Ilan University, Dept. of Mathematics,

Statistics and Computer Sciences,

Ramat-Gan, Israel

D. Branski

Departments of Pediatrics, Hadassah Medical Center,

Jerusalem 91120, Israel 